\title{
Semeadura direta na recomposição vegetal de áreas ciliares: efeitos da sazonalidade, uso do solo, exclusão da predação, $e$ profundidade na sobrevivência inicial
}

\section{Reforestation of riparian areas by direct seeding: the effects of sazonality, soil use, exclusion of predation, and depth on initial survival}

\author{
Ubirajara C. Malavasi ${ }^{1 *}$; Gasparino, D. ${ }^{2}$; Malavasi, M.M ${ }^{1}$
}

\begin{abstract}
Resumo
O ensaio testou os efeitos da sazonalidade, uso do solo, profundidade de semeadura e exclusão da predação na sobrevivência após 90 dias da semeadura direta de canafístula (Peltophorum dubium (Spreng.) Taub.) e de timburi (Enterolobium contortisiliquum (Vell.) Morong.) em áreas de domínio ciliar alteradas antropicamente. Foram efetuadas semeaduras na primavera (setembro), e verão (dezembro) de 2002, assim como no outono (março), e inverno (junho) de 2003 sempre na segunda semana após o início da estação, na superfície e à profundidade de $2 \mathrm{~cm}$, com e sem a exclusão da predação. $O$ ensaio foi implantado em propriedades rurais limítrofes ao riacho Guavirá, oeste do Paraná. Quando semeadas a profundidade de $2 \mathrm{~cm}$ na primavera e verão, as sementes das duas espécies apresentaram sobrevivência de $36,6 \%$ e $25,5 \%$ para áreas com produção de grãos e pastagem, respectivamente, e de 9,73\% para áreas sob remanescentes arbóreos. A sobrevivência de germinantes após 90 dias, em áreas de domínio ciliar utilizada para produção tanto de grãos como de pasto, foi maior do que aquela sob a proteção de remanescentes arbóreos.

Palavras-chave: Canafístula, timburi, desenvolvimento inicial, predação de sementes
\end{abstract}

\begin{abstract}
This study reports the effects of seasonality, depth of seeding, and predation exclusion on the early survival of Peltophorum dubium (Spreng.) Taub. and Enterolobium contortisiliquum (Vell.) Morong. seeds used to re-vegetate riparian areas. The study used proprieties along Guavira stream, in the west Parana region. Direct seeding was performed in the second week of spring, summer, autumn, and winter. Seeds were placed at the soil surface or at $2 \mathrm{~cm}$ depth. Predation exclusion was accomplish by a metal cage. The spring and summer seeding had survival rates of $36.6 \%$ and $25.5 \%$ in areas used for grain or pasture production and only $9.73 \%$ for areas under forest patches when seeded at $2 \mathrm{~cm}$ depth. In general, during all seasons germinant survival was higher in altered areas than under forest patches. Key words: Canafístula seeds, timburi seeds, early development, seed predation
\end{abstract}

\footnotetext{
1 Centro de Ciências Agrárias. Rua Pernambuco 1777. Fone: 45 254-3216 Ramal 221; Fax: 45 254-3216. Marechal Candido Rondon, PR. CEP 85960-000

2 Mestre em Produção Vegetal, Biologia, Maringá, PR. CEP 87080-280

* Autor para correspondência.
} 


\section{Introdução}

Segundo Seitz (1994), a regeneração natural da vegetação é o procedimento mais econômico para a recomposição vegetal de áreas desmatadas. Em geral, ambientes desmatados podem ser recuperados pela dinâmica natural da vegetação. Porém, quando o banco de sementes do solo está esgotado e não existe fonte adjacente de propágulos, o sucesso desse processo natural está diretamente relacionado com o grau de degradação do ecossistema (GARWOOD, 1989).

Uma das atividades para regeneração de áreas desmatadas propostas por Rodrigues e Gandolfi (2000) é o manejo do banco de sementes no solo. A dinâmica de formações florestais tropicais tem grande participação no estoque de sementes no solo, principalmente no aporte contínuo de propágulos nestas áreas ocasionado por fatores bióticos e abióticos.

No início do século XX devido à exuberância das florestas, o estado do Paraná mostrava-se detentor de grande potencial de recursos florestais. A exploração sistemática destes recursos, ou mesmo a sua substituição por culturas agrícolas, sempre foi associada à idéia de progresso. No entanto, deste processo resultou na redução alarmante da cobertura vegetal (JACOBS, 1999). Com a expansão da fronteira agrícola, a vegetação arbórea e arbustiva foi derrubada sem que houvesse aproveitamento econômico (GODAR et al., 1984). A região oeste do estado perdeu quase a totalidade da vegetação ciliar devido a requerimentos para obtenção de empréstimos agrícolas de bancos oficiais na década de 70 (FEY, 2003).

A vegetação ciliar apresenta variação de estrutura, composição e distribuição espacial em razão da freqüência de alterações que ocorrem nas áreas ciliares (DURIGAN; RODRÍGUEZ; SCHIAVINI, 2000). Além das espécies tipicamente ciliares encontradas, essas áreas também suportam espécies típicas de terra firme, e assim são consideradas como fontes importantes de sementes para o processo de regeneração natural (KAGEYAMA; GANDARA, 2000). As características da vegetação ciliar habilitam-na como elemento importante na manutenção da biodiversidade regional.

Estudo recente demonstrou que o banco de sementes do solo em áreas de domínio ciliar utilizadas para produção de grãos e pastagem no oeste paranaense não possui número suficiente de propágulos viáveis para a revegetação ciliar (GASPARINO, 2003). Árvores exercem papel chave como matrizes de sementes, fornecedoras de alimento e habitat para a fauna e como geradoras de micro-sítios diferenciados que contribuem para a formação de diversas eco-unidades. A revegetação de áreas onde inexistem fontes de propágulos nas imediações possui maior probabilidade de insucesso (PERRY; BORCHERS, 1990).

Variações nas condições climáticas que afetam germinação e sobrevivência de germinantes bem como variações espaciais do substrato e conseqüente efeito no recrutamento e abundância de locais seguros para germinantes têm sido reportadas na literatura (ARNOTT; MAC ARTHUR; DEMERS, 1971; MINORE, 1972; GEIER-HAYES, 1987; HARMON; FRANKLIN, 1989; ANDERSON; WINTERTON, 1996; KROHN et al., 2001). A sobrevivência dos germinantes depende da estratégia de dispersão da espécie e das condições microclimáticas (PERRY, 1994). A sobrevivência inicial compreende o número ou porcentagem de germinantes que atinge um estádio de desenvolvimento independente das reservas da semente (RIBBENS; SILANDER; PACALA, 1994). Timburi e canafístula são espécies florestais potencialmente utilizáveis para a recomposição vegetal de áreas ciliares no oeste paranaense.

Este ensaio quantificou o efeito da sazonalidade, da exclusão da predação, e da profundidade de semeadura na sobrevivência inicial de germinantes de duas espécies florestais semeadas diretamente em áreas de domínio ciliar utilizadas para a produção de grãos, pastagem e sob a proteção de remanescentes arbóreos nativos. 


\section{Material e Métodos}

O ensaio foi instalado em propriedades rurais limítrofes ao riacho Guavirá, município de Marechal Cândido Rondon, PR que utilizam a área de domínio ciliar para a produção de grãos ou pastagem, ou que ainda possuem remanescentes vegetais. As áreas experimentais estão situadas entre as latitudes de $24^{\circ}$ $31^{\prime} 00^{\prime \prime}$ e $24^{\circ} 34^{\prime} 00^{\prime}$ ' S, e entre as longitudes de $54^{\circ}$ $02^{\prime} 00^{\prime \prime}$ e $54^{\circ} 06^{\prime} 00^{\prime \prime}$ W. A altitude média é de 420 $\mathrm{m}$, com clima caracterizado como sub-tropical úmido, temperatura média mínima de $14^{\circ} \mathrm{C}$ e média máxima de $28^{\circ} \mathrm{C}$. O solo é classificado como Latossolo Vermelho eutroférrico - Lvef(EMBRAPA, 1999). Cada tipo de uso do solo foi representado por três propriedades rurais aleatoriamente escolhidas dentre as 75 situadas no trecho inicial de 6 kilometros do riacho.

Em cada propriedade a área experimental constou de um reticulado formado por cinco linhas de $100 \mathrm{~m}$ de comprimento, espaçadas $3 \mathrm{~m}$ entre si. Em cada linha foram marcados vinte e cinco pontos espaçados $4 \mathrm{~m}$, totalizando 125 pontos. O reticulado foi demarcado a $15 \mathrm{~m}$ da margem do riacho para evitar trechos com afloramento rochoso. Em cada área experimental foram sorteados seis pontos. Em cada ponto, foi instalado um conjunto formado por 8 sulcos de $3 \mathrm{~cm}$ de profundidade e $1,5 \mathrm{~m}$ de comprimento distantes $20 \mathrm{~cm}$ entre si. Em cada conjunto, os quatro primeiros sulcos foram semeados com canafístula, com dois sulcos utilizados para semeadura na superfície e dois com semeadura a profundidade de $2 \mathrm{~cm}$, enquanto os outros quatro sulcos foram semeados similarmente com timburi. Foram utilizadas 30 sementes previamente embebidas por 24 horas em água a temperatura ambiente por metro linear para cada combinação de espécie, profundidade de semeadura, uso do solo, e exclusão a predação. A semeaduras foram realizadas em uma das faces do sulco para facilitar as observações.

Em cada propriedade, três pontos receberam uma estrutura metálica $(1,5 \mathrm{~m} \times 1,5 \mathrm{~m} \times 0,50 \mathrm{~m})$ construída com vergalhões de ferro, e recoberta com malha metálica de $10 \mathrm{~mm}$ para exclusão de pássaros e pequenos roedores. As semeaduras foram efetuadas na primavera (setembro) e verão (dezembro) de 2002 assim como no outono (março) e inverno (junho) de 2003, sempre na segunda semana após o início da estação.

Foram testadas sementes de canafístula (Peltophorum dubium (Spreng.) Taub.) coletadas em março-abril/2002, e de timburi (Enterolobium contortisiliquum (Vell.) Morong.) coletadas nos meses de junho-julho/2002. As sementes foram escarificadas mecanicamente em laboratório com lixa $\mathrm{n}^{\circ} 80$ para madeira.

A sobrevivência foi expressa como o percentual dos germinantes anotada ao final de 90 dias após semeadura direta. A análise dos resultados utilizou um delineamento em blocos (propriedades) completamente casualizados (BCC) em esquema fatorial com três tipos de uso do solo (produção de grãos, produção de pasto, e sob remanescentes arbóreos), duas espécies (canafístula e timburi), duas profundidades de semeadura (na superfície, e a 2 $\mathrm{cm}$ ), e exclusão a predação (presença ou ausência de estrutura metálica) com três repetições.

Os dados originais foram transformados em arcoseno da raiz quadrada da percentagem dividido por 100 para obter distribuição normal dos resíduos, e submetidos à análise de variância do programa SAEG. A comparação das médias foi realizado com o teste de Tukey a 5 \% de significância.

\section{Resultados e Discussão}

A análise de variância com dados da primeira época de semeadura (primavera/2002) indicou que somente a interação profundidade de semeadura $\mathrm{x}$ uso do solo foi estatisticamente significativa $(\mathrm{P}<$ $0,05)$. O intervalo de 90 dias após semeadura encontra respaldo na literatura. De acordo com Meneghello e Mattei (2004), o período mais crítico para o estabelecimento de mudas de timburi, canafístula e cedro em Pelotas, RS foi de 30 dias. Quando semeadas na superfície do solo, a sobrevivência foi 
zero (média $<0,01 \%$ ) em todos usos do solo. Quando semeadas a profundidade de $2 \mathrm{~cm}$, as sementes das duas espécies apresentaram sobrevivência de 36,6 \% e 25,5 \% para áreas com produção de grãos e pastagem, respectivamente, e de 9,73\% para áreas sob remanescentes arbóreos. Apesar de inexistir efeito estatisticamente significativo do uso das estruturas metálicas foi constatada a presença de formigas nas áreas sob remanescentes arbóreos.

A segunda época de semeadura (verão/2002) caracterizou-se por apresentar resultados similares àqueles da época de semeadura anterior apesar de uma maior irregularidade da precipitação.
A análise dos dados resultantes da terceira época de semeadura (outono/2003) revelou que a interação tríplice (uso do solo $\mathrm{x}$ profundidade de semeadura $\mathrm{x}$ espécie) foi estatisticamente significativa ( $\mathrm{F}=4,55 \mathrm{e}$ $\mathrm{P}=0,0153$ ). Sob a proteção de remanescentes arbóreos, a profundidade de semeadura e a espécie não influenciaram a sobrevivência. Nas áreas utilizadas para a produção de grãos e de pastagem, no entanto, foram anotadas as maiores sobrevivências quando as sementes foram semeadas a $2 \mathrm{~cm}$ de profundidade (Tabela 1 ).

Tabela 1. Percentagem de sobrevivência de canafístula e timburi, aos 90 dias após semeadura direta no outono/2003, em resposta a tipos de uso do solo e profundidade da semeadura.

\begin{tabular}{|c|c|c|c|c|c|c|}
\hline \multirow{3}{*}{ Espécie } & \multicolumn{6}{|c|}{ Uso do solo } \\
\hline & \multirow{2}{*}{\multicolumn{2}{|c|}{$\begin{array}{c}\text { Remanescente arbóreo } \\
\begin{array}{c}\text { Profundidade da } \\
\text { semeadura }\end{array} \\
\end{array}$}} & \multirow{2}{*}{\multicolumn{2}{|c|}{$\begin{array}{c}\text { Produção de grãos } \\
\text { Profundidade da semeadura }\end{array}$}} & \multicolumn{2}{|c|}{ Pastagem } \\
\hline & & & & & \multicolumn{2}{|c|}{ Profundidade da semeadura } \\
\hline & superfície & $2 \mathrm{~cm}$ & superfície & $2 \mathrm{~cm}$ & superfície & $2 \mathrm{~cm}$ \\
\hline Canafístula & $0 \mathrm{a}$ & $1,94 \mathrm{a}$ & $0,83 \mathrm{~b}$ & $16,11 \mathrm{a}$ & $1,39 \mathrm{~b}$ & $14,72 \mathrm{a}$ \\
\hline Timburi & $0,28 \mathrm{a}$ & $1,94 \mathrm{a}$ & $0 \mathrm{~b}$ & $3,89 \mathrm{a}$ & $2,50 \mathrm{~b}$ & $3,61 \mathrm{a}$ \\
\hline
\end{tabular}

Médias na linha de cada uso do solo, seguidas da mesma letra não diferem estatisticamente pelo teste de Tukey $(\alpha=0.05)$.

A análise referente aos resultados da quarta época de semeadura (inverno/2003) resultou em três interações significativas $(\mathrm{P}<0,05)$. A interação espécie $\mathrm{x}$ profundidade de semeadura revelou que P.dubium expressou maior sobrevivência tanto na superfície $(5,55 \%)$ como à profundidade de $2 \mathrm{~cm}$ $(11,5 \%)$ quando comparadas às sobrevivências de E.contortisiliquum $(0,55 \%$ na superfície e $1,61 \%$ a $2 \mathrm{~cm}$, respectivamente). Estes resultados indicam diferenças em estratégias de recrutamento (GARWOOD, 1989). De acordo com Harper (1977) e Malavasi e Malavasi (2001), sementes com maiores dimensões tendem a ser mais atrativas a predadores do que sementes de menores dimensões, pois possuem menor probabilidade de penetração no solo. A interação uso do solo x profundidade de semeadura indicou que em áreas com produção de grãos a sobrevivência foi maior $(13,83 \%)$ que em áreas de remanescentes arbóreos nativos $(2,83 \%)$ quando a semeadura ocorreu a $2 \mathrm{~cm}$ de profundidade. Similarmente, Perez, Fanti e Casali (1999) obtiveram maior germinação a profundidade de 3 e $5 \mathrm{~cm}$ em condições de campo. Por último, a interação espécie $\mathrm{x}$ uso do solo apontou que a sobrevivência dos germinantes de P.dubium foi influenciada pelo uso do solo. Os valores médios anotados foram de 32,23\%, $25,26 \%$, e 8,06 \% para áreas utilizadas com produção de pasto, com a produção de grãos, e com remanescentes arbóreos, respectivamente. A sobrevivência de $E$. contortisiliquum, ao contrário, não foi influenciada pelo fator uso do solo (média de 1,4\%).

Os valores reduzidos de sobrevivência nas condições de campo deste ensaio podem ser parcialmente justificados pela redução na germinação das sementes em função da rápida deterioração das mesmas após embebição. A germinação de sementes 
Semeadura direta na recomposição vegetal de áreas ciliares: efeitos da sazonalidade, uso do solo, ...

de canafístula apontou redução no percentual de germinação de $65,1 \%$ aos 45 dias após colheita para valores de $51,1 \%, 45,5 \%$ e $36,5 \%$ aos 90,150 , e 365 dias após colheita, respectivamente, quando armazenadas em saco de papel e ambiente de laboratório (PEREZ; FANTI; CASALI, 1999). Sementes de timburi quando submetidas ao envelhecimento acelerado, sob condições de alta temperatura e umidade, por 84 ou 120 horas resultaram em $0 \%$ de germinação em condições de laboratório (SIRTOLI et al., 2003).

Os resultados deste ensaio são coincidentes com os reportados por Dutra et al. (2002) que trabalhando com duas estratégias de recuperação em locais submetidos à extração de bauxita em Poços de Caldas, Minas Gerais, obtiveram sobrevivência variando de 0 a $38 \%$. A profundidade de semeadura, no entanto, é específica às espécies utilizadas. Motta, Davide e Ferreira (2002) mostraram que sementes de mutamba (Guazuma ulmifolia Lam.) dispostas na superfície do solo e a $2 \mathrm{~cm}$ de profundidade apresentaram similaridade na taxa de emergência de plântulas porém maiores do que aquela resultante de sementes a $4 \mathrm{~cm}$ de profundidade. A expectativa de que haveria predação de sementes por pássaros e pequenos roedores não foi confirmada nas condições deste ensaio.

\section{Conclusões}

Os resultados permitiram concluir que o uso de estruturas metálicas com malha de $10 \mathrm{~mm}$ não influenciou a sobrevivência dos germinantes das espécies testadas 90 dias após semeadura direta em nenhuma das estações do ano.

A profundidade de semeadura de $2 \mathrm{~cm}$ resultou em maior sobrevivência do que a anotada com sementes depositadas na superfície do solo em todas as estações do ano.

A sobrevivência de germinantes em áreas de domínio ciliar utilizada com a produção tanto de grãos como de pasto foi maior do que aquela sob remanescentes arbóreos, demonstrando que estes últimos ambientes são prejudiciais para a semeadura direta de sementes previamente embebidas.

\section{Referências}

ANDERSON, L. J.; WINTERTON, A. J. Germination as a determinant of seedling distributions among natural substrates in Picea engelmannii (Pinaceae) and Abies lasiocarpa (Pinaceae). American Journal of Botany, Columbus, v. 83, p. 112-117, 1996.

ARNOTT, T. J.; MacARTHUR, J. D.; DEMERS, A. Seeding of five conifers on prepared seedspots in Quebec. Pulp And Paper Magazine Of Canada, Westmount, v. 72, n. 7, p. 92-93.1971.

DURIGAN, G.; RODRÍGUEZ, R. R.; SCHIAVINI, I. A heterogeneidade ambiental definindo a metodologia de amostragem da floresta ciliar. In: RODRIGUES, R. R.; LEITÃO FILHO, H. F. (eds.) Matas Ciliares: conservação e recuperação. São Paulo: Ed. USP, 2000. p. 159-167.

DUTRA, G. C.; BOTELHO, S. A.; FEREIRA, C. A. G.; DAVIDE, A. C. Avaliação do crescimento de espécies arbóreas plantadas em duas estratégias de recuperação de áreas degradadas pela mineração In: SIMPÓSIO NACIONAL DE RECUPERAÇÃO DE ÁREAS DEGRADADAS, 5., 2002, Belo Horizonte. Anais... Belo Horizonte, 2002 p. 331-33.

EMBRAPA. Sistema Brasileiro de Classificação de Solos. Rio de Janeiro: Centro Nacional de Pesquisa de Solos, 1999. 412 p.

FEY, R. Dinâmica do nitrogênio, produção de biomassa seca e concentração de nutrientes em plantas de milho em solos submetidos a efluentes da suinocultura. 2003. 38 p. Dissertação (Mestrado) - PPGAM, Unioeste, Marechal Cândido Rondon, PR, 2003.

GARWOOD, N. C. Tropical soil seed banks: a review. In: LECK, M. A.; PARKER, V. T.; SIMPSON, R. L. (eds.) Ecology of soil seed banks. San Diego: Academic Press, 1989. p. 149-209.

GASPARINO, D. Avaliação da regeneração do banco de sementes na área de domínio ciliar do córrego Guavirá em diferentes áreas de utilização. 2003. 76 p. Dissertação PPGAM, Unioeste, Marechal Cândido Rondon, PR, 2003.

GEIER-HAYES, K. Occurrence of conifer seedlings and their microenvironments on disturbed sites in central Idaho. USDA Forest Service Intermountain Research Station Research Paper, Ogden, INT. 383, 1987. 
GODAR, C. L. S.; LARA, P. F.; NORONHA, J. B.; RIBEIRO, M. V.; SARTOR, A. K. R.; VENÂNCIO, C. Diretrizes para formulação de uma política florestal para o Estado do Paraná..Curitiba: CODESUL, 1984. 303 p.

HARMON, M. E.; FRANKLIN, J. F. Tree seedlings on logs in Picea-Tsuga forests of Oregon and Washington. Ecology, Washington, v. 70, p. 48-59. 1989.

HARPER, J. L. Population Biology of Plants. London: Academic Press, 1977. p 23-110.

JACOBS, G. A. Evolução dos remanescentes florestais e áreas protegidas no estado do Paraná. In: Cadernos da Biodiversidade, Curitiba, v. 2, n. 1, p. 64-68. 1999.

KAGEYAMA, P.; GANDARA, F. B. Recuperação das áreas ciliares. In: RODRIGUES, R. R.; LEITÃO FILHO, H. F. (eds.) Matas Ciliares: conservação e recuperação. São Paulo: Ed. USP, 2000. p. 249-269.

KROHN, N. G.; SOUZA, M. A.; STEINMACHER, D. A.; SESTAK, M.; MALAVASI, U. C.; MALAVASI, M. M. Avaliação do efeito do protetor físico sobre o estabelecimento de Schizolobium parahyba em semeadura direta a campo. In.: CONGRESSO BRASILEIRO DE SEMENTES, 12., 2001, Curitiba. Resumos... Curitiba, 2001.p. 290.

MALAVASI, U. C.; MALAVASI, M. M. Influencia do tamanho da semente na germinação e no estabelecimento de espécies de diferentes estágios da sucessão vegetal. Floresta e Ambiente, Seropédica, v. 8, n. 1, p. 211-215. 2001.

MENEGHELLO, G. E.; MATTEI, V. L. Semeadura direta de timbaúva (Enterolobium contortisiliquum), canafístula (Peltophorum dubium) e cedro (Cedrela fissilis) em campos abandonados. Ciência Florestal, Santa Maria, v. 14, n. 2, p. 21-27. 2004.

MINORE, D. Germination and early growth of coastal tree species on organic seed beds. USDA Forest Service Intermountain Research Station Research Paper, Ogden, PNW-135. 1972.
MOTTA, M. S.; DAVIDE, A. C.; FERREIRA, R. A. Comportamento fisiológico de sementes de mutamba (Guazuma ulmifolia Lam. - Sterculiaceae) num banco de sementes induzido. In: SIMPÓSIO NACIONAL DE RECUPERAÇÃO DE ÁREAS DEGRADADAS, 5., 2002, Belo Horizonte: SOBRADE, 2002. p. 328-330.

PEREZ, S. C. J. G. A.; FANTI, S. C.; CASALI, C. A. Effects of storage, substrate, early aging, and sowing depth on the germination of canafistula seeds. Bragantia, Campinas, v. 58, n. 1, p. 57-68. 1999.

PERRY, D. A. Forest Ecosystems. London: The John Hopkins University Press, 1994. 649 p.

PERRY, D. A.; BORCHERS, J. G. Climate change and ecosystem responses. Northwest Environmental Journal, Seattle, v. 6, n. 2, p. 293-313. 1990.

RIBBENS, E.; SILANDER, J. A.; PACALA, S. W. Seedling recruitment in forests: calibrating models to predict patterns of tree seedling dispersion. Ecology, Washington, v. 75, n. 6, p. 1794-1806. 1994.

RODRIGUES, R. R.; GANDOLFI, S. Conceitos, tendências e ações para a recuperação de florestas ciliares. In: RODRIGUES, R. R.; LEITÃO FILHO, H. F. (eds.) Matas Ciliares: conservação e recuperação. São Paulo: Ed. USP, 2000. p. 235-248

SEITZ, R. A. A. A regeneração natural de áreas degradadas. In: SIMPÓSIO SUL AMERICANO, 1.; SIMPÓSIO NACIONAL EM RECUPERAÇÃO DE ÁREAS DEGRADADAS, 2., 1994, Foz do Iguaçu. Anais... Foz do Iguaçu, 1994. p. 103-110.

SIRTOLI, L.; SAVEGNAGO, L.; DIAS, M. T.; MALAVASI, M. M.; MALAVASI, U. C. Comportamento de sementes de timburi (Enterolobium contortisiliquum Vell.) submetidas ao envelhecimento precoce. In: CONGRESSO BRASILEIRO DE SEMENTES, 13., 2003, Gramado. Informativo Abrates..., Gramado, 2003, p. 380. 